\title{
Optimal Two Hubs Location and Network Construction for a Regional Company of WAEMU Zone
}

\author{
N'dogotar Nélio ${ }^{1,2}$, Salimata G. Diagne ${ }^{2}$ \& Youssou Gningue ${ }^{3}$ \\ ${ }^{1}$ Department of Mathematics and Informatics, Sarh University, Chad \\ 2 Department of Mathematics and Informatics, Cheikh Anta Diop University, Dakar, Senegal \\ ${ }^{3}$ Chair of Mathematics and Computer Science Dep., Laurentian University, Canada
}

Correspondence: N'dogotar Nélio, Department of Mathematics and Informatics, Cheikh Anta Diop University, Dakar, Senegal. Tel: 221-707-920-802. E-mail: neliondogotar@gmail.com

Received: February 9, 2016 Accepted: March 1, 2016 Online Published: March 16, 2016

doi:10.5539/jmr.v8n2p49

URL: http://dx.doi.org/10.5539/jmr.v8n2p49

\begin{abstract}
In this paper, the linear integer programming(LIP) was used to model two hubs location problem and network construction for a regional company of WAEMU zone. Taking account of passengers flow and the movements of planes recorded in the airports in the constraints, the model takes into account the rate of filling of the planes, one of the crucial factors for a company to maximize its profit. Minimizing the sum of the distances in the objective, the company makes savings on the fuel and minimizes its costs on aircrew which is remunerated by flight hours.
\end{abstract}

Keywords: LIP, location, hubs, network

\section{Introduction}

The hubs location problem is to structure the network for optimal use. We have this problem in transportation air, land transportation, in telecommunications networks. In air transport, airline which has ambition to perpetuate and live well economically, should structure its network entirely around one or a few hub airports, called hubs. It is essential that this pivot is provided by one (or more) Airport(s) whose traffic flow is significant compared to other airports. In this paper we solve the two hubs location problem and the air network construction for one company of the WAEMU zone. WAEMU is composed of eight countries: Benin, Burkina Faso, Ivory Coast, Guinea Bissau, Mali, Niger, Senegal and Togo (figure 1).

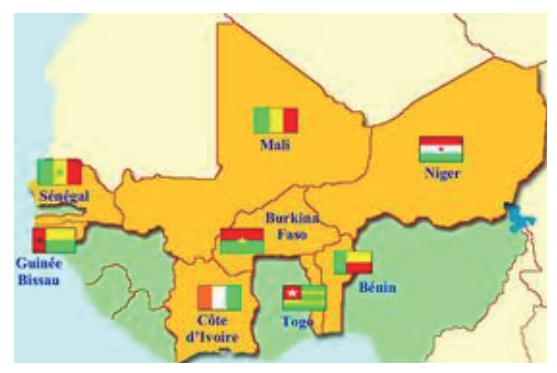

Figure 1. WAEMU map.

This number does not justify so creating two hubs considering their geographical position. However, given the terrorist threats of recent times, seen some epidemics like Ebola, so that one day the company can not stop completely at the causes of these reasons, the creation of two hubs is justified. If a company has two hubs, two situations can arise:

1. passengers to go from origin airport to destination airport, both different hubs, must go through the two hubs;

2. passengers have the opportunity to go through a single hub, or both hubs depending on the position of the origin and destination countries compared to hubs.

The hub also optimizes flight filling mostly medium distance to long distance. A long-distance is a flight lasting more than five hours of time. So if we consider a aircraft that has an average speed of $750 \mathrm{~km} / \mathrm{h}$. it takes at least $3750 \mathrm{~km}$ for to be a long-distance. no distance between any two countries of the WAEMU zone reaches $3000 \mathrm{~km}$. Therefore, we 
estimate that the first case is unrealistic. Our paper will take account the second case ie passengers have the opportunity to go through a single hub, or both hubs depending on the position of the origin and destination countries compared to hubs.

However why locating a hub or hubs for the WAEMU zone? In the field of air transport, WAEMU objectives are among others[UEMOA2002]:

- Strengthen the competitiveness of economic and financial activities of member states in the framework of an open and competitive market and a rationalized and harmonized legal environment.

- assure convergence of performance and policies of member states by the institution of a multilateral surveillance procedure

- Create between Member States a common market based on the free movement of persons, goods, services, capital and the right of establishment for persons practising independante activity or paid work, as well as on a common outside tariff and trade policy.

- establish coordination of national sectoral policies through the implementation of joint actions, and eventually, common policies especially in the following areas: human resources, territory development, agriculture, energy, industry, mining, transport, infrastructure and telecommunications.

- Harmonize, to the extent necessary for the proper functioning of the common market, the laws of the Member States and particularly the regime of fiscal system.

To achieve its objectives, it use instruments such:

- a policy of transport and telecommunications;

- an industrial and mining policy;

- a common and integrated market

This paper has for ambition to contribute in hubs location in air transport because the airport today is a way of penetration of the global economy in the regional or national economy. Therefore, airports that will be located as hubs should be the main air gateways in WAEMU zone and commercial exchanges place and then can be one of major poles of development in the WAEMU zone.

Several hub location problems are studied in the literature: the problems of p-hub median, hub location problem without capabilities, problems of p-hub center, hub cover problem. For more information on the problems of hubs locations, see [CAMPBELL2002] and [CAMPBELL2012]. One state of the art on hubs location problem have been studied by A. SIBEL and Y. KARA[ALUMUR2007] and by CAMPBELL J.F [CAMPBELL1987]. A linearization of this formulation is given by CAMPBELL in[CAMPBELL1994]. IVAN Contreras and al used the branch and price[Contreras2011] and the lagrangian relaxation[Contreras2009] for the capacitated hub location problem with single assignment. Rodriguez et al[Rodriguez2007] have solved the hub location and single assignment problem with great capacity by the Branch and Price. We, we propose a linear integer programming model with airport capacity. the capacity of the airport consists of the number of passengers recorded and the number of annual movements

\section{Method}

locate a hub or hubs consists to choose 1, 2, 3, etc airport (s) among several (therefore integer values) according to a number of criteria while minimizing operating costs. What brought us to use linear programming method in whole numbers for to model our problem. The constraints and the objective function are linear and variables are integers.

We consider a graph $G=\{N, A\}$, where $N=\{1,2, \ldots, n\}$ is the set of nodes corresponding to airports origin / destination and $A$ the set of lines (edges) connecting the different airports. The following parameters will be used

\subsection{Definition of Parameters}

- N: set of the airports that are potential hubs

- E: set of WAEMU airports satisfying capacity constraints

- H: set of countries outside the WAEMU zone 
- $d_{i j}$ : the distance between nodes $i$ and $j$

- if $i$ is the origin and $j$ the destination then the path from $i$ to $j$ is of the form $i-k-m-j$ where $k$ and $m$ are hubs which $i$ and $j$ are attached respectively. it will be noted this distance $\delta_{i k m j}$ et $\delta_{i k m j}=d_{i k}+d_{k m}+d_{m j}$

- $P_{i}$ : the number of passengers recorded in one year at the node(airport) $i$

- $M_{i}$ : the number of movements recorded in one year at the node(airport) $i$

- $\bar{X}$ : the arithmetic mean of the passengers number recorded in the WAEMU zone.

$$
\bar{P}=\frac{1}{|N|} \sum_{i=1}^{|N|} P_{i}
$$

- $\bar{M}$ : the arithmetic mean of the movements number recorded in the WAEMU zone.

$$
\bar{M}=\frac{1}{|N|} \sum_{i=1}^{|N|} M_{i}
$$

Our objective is to determine two hubs and the number of airports attached to them so as to minimize the total sum of the distances. We then define two decision variables. To indicate the hub $\forall k \in N$

$y_{k}= \begin{cases}1 & \text { If the hub is located in } \mathrm{k} \\ 0 & \text { otherwise }\end{cases}$

To show that the flow from original $i$ to destination $j$ goes by at least one of the hubs $k$ and $m, \forall i, k, m, j \in N$

$x_{i k m j}= \begin{cases}1 & \text { If flow from } \mathrm{i} \text { to } \mathrm{j} \text { goes via } \mathrm{k} \text { and } / \text { or } \mathrm{m} \\ 0 & \text { otherwise }\end{cases}$

\subsection{Mathematic Formulation}

Our formulation of hub location problem by linear integer programming with airport capacities is as follows:

$$
\begin{aligned}
m i n z & =\sum_{i \in N \cup H} \sum_{k \in E} \sum_{m \in E} \sum_{j \in N \cup H} \delta_{i k m j} x_{i k m j} \\
\sum_{i \in N} y_{k} & =2 \\
\sum_{k \in N} \sum_{m \in N} x_{i k m j} & =1 \quad \forall i, j \in N \\
x_{i k m j} & \leq y_{k} \quad \forall i, k, m, j \in N \\
x_{i k m j} & \leq y_{m} \quad \forall i, k, m, j \in N \\
\sum_{k \in N} P_{k} y_{k} & \geq \bar{X} \\
\sum_{m \in N} P_{m} y_{m} & \geq \bar{X} \\
\sum_{k \in N} M_{k} y_{k} & \geq \bar{M} \\
\sum_{m \in N} M_{m} y_{m} & \geq \bar{M} \\
\sum_{k \in N} d_{i k} y_{k} & \leq d_{i m} \quad \forall i, m \in N \\
\sum_{m \in N} d_{i m} y_{m} & \leq d_{i k} \quad \forall i, k \in N \\
y_{k} & \in\{0,1\} \quad \forall k \in N \\
x_{i k m j} & \in\{0,1\} \quad \forall i, k, m, j \in N
\end{aligned}
$$

The objective function (1) minimizes the sum of distances from an origin to a destination. Constraint (2) means that exactly two hubs are to locate. Constraints (3) mean that each pair origin / destination must be assigned to exactly one 
pair of hubs. As $\mathrm{k}$ may be equal to $\mathrm{m}$ in (3), the flow between an original $i$ and a destination $j$ can pass through a single hub. Constraints (4) and (5) stipulate that the flow from an original $\mathrm{i}$ to destination $\mathrm{j}$ can only be assigned to the hub located in $\mathrm{k}(4)$ or $\mathrm{m}(5)$. Constraints (6), (7), (8) and (9) indicate that if the hubs are located in $k$ and $m$ then the number of passengers registered and the number of movements in the airports for a year must be at least beyond the average of passenger and of movements in the different airports. constraints (10) and (11) are the constraints of joining to hubs ie if the distance of an airport $i$ to the hub $k$ is smaller than the one $i$ to hub $m$ then the airport $i$ is joined to the hub $k$ and vice versa. The constraints (12) and (13) show that the decision variables are binary variables.

\subsection{Resolution Method}

\subsubsection{Resolution Algorithm}

\section{Stage 1}

- Enter the number of passengers

- Calculate the average of passengers

- Enter the number of movements

- Calculate the average of movements

\section{Stage 2}

- Determine the set $N_{1}$ of airports having more passengers than the average of passengers

- Determine the set $N_{2}$ of movements having more movements than the average of movements

- Determine the set $N_{3}$ of airports intersection of $N_{1}$ and $N_{2}$.

\section{Stage 3}

- Calculate the distance of each airport of the set for all other airports

- class the distances by ascending

- The first two values give the two corresponding hubs

\section{Stage 4}

- Calculate the distances between these two hubs airports rated 1 and 2 and the other airports

- Compare these distances. If the distance from any airport i to hub 1 is less than the distance of this airport to hub 2 then the airport $\mathrm{i}$ is joined to the hub 1 . Otherwise it is joined to the hub 2.

\subsubsection{Description of the Resolution Method}

Our resolution of the model is done in two stages:

1. we determine the set $\mathrm{E}$ of airports in the WAEMU zone which verify the capability criteria. We do afterwards $C_{|E|}^{2}$ (combination of 2 into Cardinal E) airports and we retain the one that minimizes the objective function (1). Both airports are then the airports hubs

2. The hubs are known, we seek to make the assignment of airports to hubs ie we seek to check the criteria (10) and (11). For that we check if $d_{i k} \leq d_{i m}$ then the airport $i$ is assigned to hub $k$.

\section{Results}

We used for the simulation the Python 2.7 software.

For the first step, the data used are those of Enac air traffic data: global traffic in 2012 


\subsection{Data}

The data used are summarized in Tables 1, 2 and 3

Table 1. Passengers et movements recorded

\begin{tabular}{ccc}
\hline aroports de & Passagers & Mouvements \\
COO & 481389 & 5890 \\
OUA & 405000 & 12000 \\
ABJ & 646942 & 19212 \\
OXB & & \\
BKO & 533054 & 10348 \\
NIM & 215872 & 7631 \\
DKR & 1732687 & 28014 \\
LFW & 472313 & 4431 \\
\hline
\end{tabular}

Table 2. Distances between differents airports of WAEMU zone.

\begin{tabular}{ccccccccc}
\hline & COO & OUA & ABJ & OXB & BKO & NIM & DKR & LFW \\
COO & 0 & 789,734 & 710,061 & 2073,561 & 1324,38 & 789,308 & 2363,256 & 127,041 \\
OUA & 789,734 & 0 & 828,943 & 1539,151 & 699,712 & 418,901 & 1749,6 & 748,308 \\
ABJ & 710,061 & 828,943 & 0 & 1483,128 & 918,532 & 1130,158 & 1818,472 & 583,025 \\
OXB & 2073,561 & 1539,151 & 1483,128 & 0 & 840,934 & 1942,843 & 373,591 & 1961,805 \\
BKO & 1324,38 & 699,712 & 918,532 & 840,934 & 0 & 1102,383 & 1061,459 & 1231,227 \\
NIM & 789,308 & 418,901 & 1130,158 & 1942,843 & 1102,383 & 0 & 2127,439 & 815,437 \\
DKR & 2363,256 & 1749,6 & 1818,472 & 373,591 & 1061,459 & 2127,439 & 0 & 2258,757 \\
LFW & 127,041 & 748,308 & 583,025 & 1961,805 & 1231,227 & 815,437 & 2258,757 & 0 \\
\hline
\end{tabular}

Table 3. Distance between hubs and the countries out of WAEMU zone

\begin{tabular}{ccc}
\hline & PCD & Casablanca \\
ABJ & 4887.863 & 3158.158 \\
DKR & 4219.084 & 2309.764 \\
\hline
\end{tabular}

\subsection{Results of the First Stage}

After simulation, the average of passengers is $\bar{x}=560907$ and that of the movements is $\bar{M}=10940$. Only two airports verify capacity constraints. Those are the airports of ABJ(Abidjan) and DKR(Dakar). Both airports are then the two hubs

\subsection{Results of the Second Stage}

For the second stage after checking constraints (10) and (11), airports are assigned to two hubs as shown in the following network:

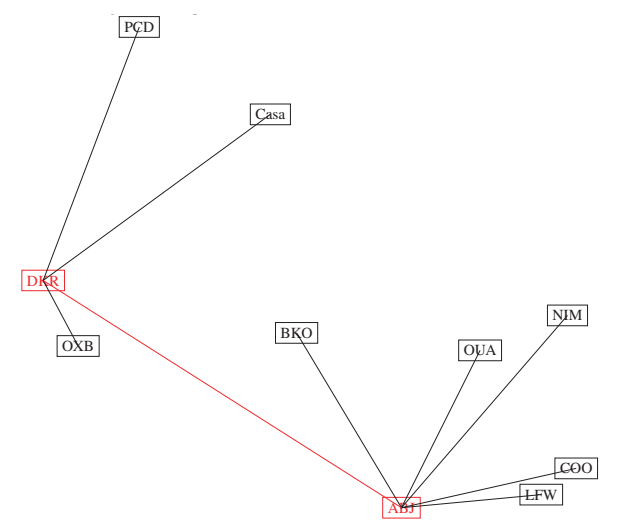

Figure 2. Example of a network with two hubs for the WAEMU zone. 


\section{Discussion}

All countries of the UEMOA zone except Guinea-Bissau are assigned to the Hub of Abidjan. Given the geographical position of both countries: Ivory Coast and Senegal, the hub of Abidjan can be seen as the gateway into the WAEMU zone of the passengers of Central Africa, Southern Africa. Guinea-Bissau and France are assigned to the hub of Dakar. The Hub of Dakar can be seen as the gateway into the WAEMU zone of the passengers from Europe, Asia, and America represented by PCD (Paris Charles Degaule) and Arabic Africa represented by Casa (Casablanca in Morocco)

\section{Conclusion}

This paper is a contribution of mathematical sciences at the hubs location and at network construction for an airline of the WAEMU zone. This contribution is motivated by ANACIM (National Civil Aviation Agency and Meteorology). We developed a model that allows one hand to determine two hubs for the WAEMU zone and secondly to build a network for an air company of this sub-regional. The results of our simulations, given the data we have, give the airports of Abidjan in Ivory Coast and of Dakar in Senegal like hubs. These results confirm the role of these two countries into the WAEMU and their economic weight compared to other countries in the zone. As perspectives, we intend to take into account the airports of the cities not capitals of the WAEMU zone, like the airport Blaise Diagne in Senegal, airport of Yamoussoukro in Ivory Coast, Airport of Bobo Dioulasso in Burkina Faso, etc.

\section{References}

CAMPBELL, J. F. (1994). Integer programming of discrete hub location problems. European Journal of Operational Research. pp. 387-405. http://dx.doi.org/10.1016/0377-2217(94)90318-2

CAMPBELL, J. F., ERNEST, A. T., \& KRISHNAMOORTHY, M. (1987). Hub location problems. In H. Hamacher and Z. Drezner, editors, location theory: Application and theory.

CAMPBELL, J. F, Ernest, A. T., \& Krishnamoorthy, M. (2002). Hub location problems. Facility location: applications and theory. (pp. 373-407).

CAMPBELL, J. F., \& OKelley, M. E. (2012). Twenty-five years of hub location research. Transportation Science. pp. 153-169. http://dx.doi.org/10.1287/trsc.1120.0410

Commission UEMOA. (2002).Programme commun de transport arien dans les etats membres de l'UEMOA.(pp. 3)

IVAN, C., Dias Juan, A., \& Fernandez, E. (2009). Lagrangian relaxation for the capacities hub location problem with single assignment.(pp. 483-505). Regular Article.

IVAN, C., Dias Juan, A., \& Fernandez, E. (2011). Branch and price for large-scale capacitated hub location problems with single assignment. INFORMS Journal on Computing. pp. 41-55.

Rodiguez, V., Alvarez, M. J., \& Barcos, L. (2007). Children of color: Psychological interventions with minority youth. Logistics and Transportation Review. pp.495-505.

Sibel, A., \& Kara Bahar, Y. (2007). Network hub location problems : The state of the art. European Journal of Operational Research.

\section{Copyrights}

Copyright for this article is retained by the author(s), with first publication rights granted to the journal.

This is an open-access article distributed under the terms and conditions of the Creative Commons Attribution license (http://creativecommons.org/licenses/by/3.0/). 